\title{
SER JOVE AMB EL PROFESSOR ARANGUREN
}

\author{
Josep Maria Carandell \\ (Escriptor)
}

José Luis López Aranguren va ser catedràtic a la facultat de Filosofia de la Universitat Central de Madrid de l'any 1955 al 1965. El seu accés a la Universitat va ser una mena d'auto sacramental d'una intensitat i d'un dramatisme inoblidables. Jo acabava de passar dels cursos de comuns de Filosofia i Lletres, a la Universitat de Barcelona, als d'especialitat de Filosofia «pura», a la de Madrid, i vaig assistir a les sessions públiques de les oposicions a la càtedra d'Etica, que tenia com a principals aspirants el valencià pate Todolí $\mathrm{i}$ el castellà Aranguten. En els medis universitaris sabíem que el primer representava la filosofia escolàstica clàssica, i que el segon portava els aires dels filòsofs actuals. En general, les nostres predileccions estaven perfectament clares. Però no ens podíem ni imaginar fins a quin punt ambdós aspirants es convertirien en fetotges enemics al llarg de les oposicions. Todolí, vestit amb l'hàbit blanc del seu orde, era un home primari, sanguini, violent, medieval, que em feia pensat en sant Vicent Ferrer. Aranguren representava l'altra cara de la moneda: era un laic ben vestit, de figura molt prima, de pensament agilíssim, irònic i sarcàstic, semblant als catòlics laics francesos. Todolí acusava Aranguren de criptoprotestant i Aranguren, Todoli de «tonto». El president del tribunal, el doctor Font i Puig, amic del meu pare i professor meu a la facultat barcelonina, estava desesperat i desolat. La violència, oberta en el valencià i soterrada en el castelìà, l'exasperava, i, escudant-se en l'idioma català, em deia al final de cada sessió que patia moltíssim i que la pugna apatentment ideològica i profundament temperamental se li escapava de les mans. Font i 
Puig, sempre vestit de negre, ni era medieval ni era modern: exa un pto. fessor del segle XIX, de maneres elegantment pedants i de paraula pondetada.

AI Ministeri d'Educació, amb Ruiz Giménez, regnaven aires de renovació, i per aquest motiu la intelligència i l'actualitat varen poder triomfar sobre la retòrica inquisitorial i l'integrisme. El Mal va aconseguit derrotar el Bé en aquell auto sacramental de formes tradicionals però de significat modern. Així va ser com els estudiants vàrem poder terit Aranguren com a catedràtic d'Etica, amb l'assignatura de Sociologia acumulada a la càtedra, i, sobretot, per primera vegada en la nostra vida universitària vàrem saber que allò que més profundament desitjàvem, que la filosofia fos una activitat mental viva, era possible. Aranguren es convertí immedia tament en mestre, en incitador intellectual, en amic.

Per això mateix, la relectura del seu assaig $L a$ juventud europea, que va ser publicat per l'editorial més innovadora del país, la Seix Barral, l'any 1961, resulta avui estranya. És un retrat de la nostra generació en aquells anys en què ens formàvem, $i$ del mateix professor Aranguren, ja en plena activitat de subversió dels valors universitaris. I no correspon als nostres records. ¿Com és possible, em demano, que presenti en aquest assaig una joventut $\tan$ assenyada, tan escèptica, $\tan$ que toca de peus a terra, tan ben acomodada a la vida familiar, tan desitjosa d'integrar-se en la societat? Jo recordo els meus companys de la facultat de Barcelona: tots ells s'havien fet comunistes o participaven activament en els aldarulls $\mathrm{i}$ revoltes universitaris, i també moltes noies es llançaven pel camí de la protesta. I recordo els meus companys de la universitat madrilenya i, més encara, els del Collegi Major en el qual jo vivia: a final de la dècada dels cinquanta -objecte de l'estudi d'Aranguren- els estudiants estaven passant a marxes forçades de l'ambient de la Casa de la Troya al d'Els dimonis de Dostoiewski. En el si de les famílies, les relacions pares-fills començaven a presentar l'aspecte de les batalles campals que setien ja corrents en la dècada dels seixanta. La poesia social, «arma de combat», ja feia estralls entre l'élite universitària, amb la característica paradoxal que el materialisme -d'aspiració científica, més que real- era la brasa del nou idealisme flamejant. La revolució -antiburgesa, anticonvencional, europeista, prosoviètica, demagògica, subversiva - havia ja arrelat en l'ànim dels joves més preocupats per la cosa pública. L'avantguarda proletària començava a fer sentir els seus atacs horitzontals als murs del sindicat vertical. En genetal, es notava en el país la voluntat de canvi, d'obertura a Europa, de mínimes llibertats, d'acabar d'una vegada amb el complex de viure cent anys endarrerits respecte als països avançats. $I$, insisteixo, el mateix Aranguren $\rightarrow$ com alguns pocs ptofessors d'altres universitats- sabia perfecta- 
ment que la seva docència era, en boníssima part, invitació a la llicència.

Jo vaig seguir el professor Aranguren fins al final de la cartera, l'any 1957. L'estiu del 1956 vaig ser a Munic, on, en lloc de participar en el curs per a estrangers, em vaig integrar en una comuna beatnik. Era el temps en què jo menyspreava anàrqquicament la societat $i$, en particular, les. dones, per haver-les idolatrat massa. En acabar la carrera vaig anar a Harnburg a fer el doctorat, i em sentia molt més progressista que els estudiants. alemanys; gairebé en la mateixa ona que els estudiants del Tercer Món, que, entre classe i classe, ens llegien poemes i manifestos tevolucionaris. En els anys 1960 i 1961, quan Aranguren escrivia i publicava l'assaig del qual tractern, jo havia fugit encara més lluny, al Japó, ja interessat per la sociologia i ben conscient de l'irresolt «problema social». La meva pròpia experiència, doncs, i l'expetiència que tenia dels ambients que m'envoltaven, no coincideix de cap manera amb l'anàlisi que estava fent Aranguren. Penso que, entre l'Aranguren pensador, professor d'Etica, catòlic pre-conciliar i incitador del pensament $i$ de l'acció, per una banda, i l'Aranguren sociòleg, per l'altra, hi havia un gap encara no salvat. De fet, la sociologia sempre ha estat la ciència acientífica més desmitificadora de les aspiracions i els ideals dels humans. Refreda, com deien que una dutxa refreda la libido.

Recordo que un amic meu, comunista acèrrim, em va contestar, a la. meva pregunta de si ell havia acceptat l'eutocomunisme en el moment d'imposat-se, «jo sóc eurocomunista de tota la vida». Vaig explicar moltes vegades aquesta anècdota, com a exemple que, per als comunistes, les decisions actuals tenen efectes retroactius, fins que un bon dia em vaig adonar que jo feia el mateix en molts aspectes de la meva vida. Per això torno a repensar aquells anys -1959, 1960-, a fi i efecte de comprovar si la societat del moment era tan protestatària com em diu la memòria automàtica. L'Alemanya d'aquell moment, que com a mínim oferia una part de la «joventut europea» analitzada per Aranguren, es correspon en línies generals a aquesta anàlisi. De fet jo vaig llegir el libre de Schelsky Die skeptische Generation (1958) en el mateix temps que el professor Aranguren, $i$ com a ell em va resultar una radiografia molt real -i molt teveladora- del temps present. Em va semblar que l'apoliticisme, l'escepticisme, la libertat sexual $i$ altres temes alemanys eran un desideràtumn per a nosaltres, polititzats per necessitat, creients com soldats en Iluita, reprimits de mena, etcètera. Un parell d'anys abans, per altra banda, jo havia fet un estudi sobre el que pensen els espanyols sobre Alemanya, encarregat pel professor Aranguren. Ell, generosament, l'utilitzà en l'escrit que publicà a la tevista alemanya «Documente», citant-me, $\mathrm{i}$ després el va incloure en el mateix volum de La juventud europea y otros ensayos. Doncs 
bé, aquell treball universitari refiecteix la mateixa imatge moderada, realista $i$ gens revoltosa que Aranguren presenta en l'assaig sobre la joventut, tot i ser jo, suposadament, un protestatari. Més encara: les meves relacions amb una noia alemanya $\dot{i}$ el casament amb ella l'any 1959, així comn la majoria de les nostres converses, presenten una esgarrifadora semblança amb allò que diu Aranguren d'aquell temps. Mai no heu vist una parella més pacífica, més assenyada, més desitjosa de ser feliç (i que duri) i més creadora d'una família "com cal», que la nostra. Miro les fotografies d'aquell temps $i$ em veig $i$ ens veig com gent de l'antic règim, amb unes caretes tan necessitades de simpatia i comprensió, amb uns vestidets tan «adients», en uns paisatges $\tan i \tan$ convencionals, que una rosa no deu tecordar amb menys sorpresa que un dia va ser poncella, inclosa la cursileria insigne d'aquesta parauleta. Per dessota de les actituds públiques, i pel damunt de les iflusions utòpiques, veig que el gros de la societat era com Aranguren diu, i la seva fotografia sociològica quedatà com a darrer tetrat d'un temps que James Dean i molts altres varen assassinar amb monades de timidesa $o$ amb violències de rock i de manifestacions.

Crec, en resum, que a l'assaig d'Aranguren li falten les referències sibillines - per tal de passar censura- als desigs de canviar el país o de fugir que teníem aleshores, com a botó de mostra d'una gran insatisfacció i d'un idealisme que s'estenia dia a dia. Crec, també, que el conjunt de la societat i de les nostres vides era encara molt «etsenhowerià» i molt fill d'aquell règim que ens mantenia infants en plena joventut. Crec, finalment, que, en l'assaig, Aranguren va mostrar el seu aspecte més amable -objectivat en ciència - per tal de no agreujar els perills. Quan l'any 1963 vaig participar en un apassionant seminari sobre Sartre que feia el professor Aranguren, aleshores aquest ja havia llençat la tovallola de la possible convivència en la universitat franquista $i$, o bé ja no creia que el que bavia escrit tres anys abans fos cert, o bé ja no ho volia creure. Perquè llavors ja tots teníem consciència que el futur havia començat. 